\title{
Correlation of the maxillary sinus volume with gender and some of craniofacial indices using cone beam computed tomography
}

\author{
Shahab Etemadi ${ }^{1}$, Golnaz Seylavi*2 ${ }^{* 2}$ and Afshin Yadegari ${ }^{3}$ \\ ${ }^{1}$ Assistant Professor, Department of Oral and Maxillofacial Radiology, Isfahan (Khorasgan) Branch, Islamic \\ Azad University, Isfahan, Iran \\ ${ }^{2}$ Post Graduate Student, Department of Oral and Maxillofacial Radiology, Isfahan (Khorasgan) branch, \\ Islamic Azad University, Isfahan, Iran \\ ${ }^{3}$ Assistant Professor, Department of Oral and Maxillofacial Surgery, Isfahan (Khorasgan) Branch, Islamic \\ Azad University, Isfahan, Iran
}

\begin{abstract}
Maxillary sinus volume is variable and thus, is a topic of interest for surgeons performing endoscopic surgeries. Also, it may be helpful for sexual identification. This study sought to measure the maxillary sinus volume using cone beam computed tomography (CBCT) and assess its correlation with gender and some craniofacial indices. In this descriptive, analytical, cross-sectional study, CBCT scans of 70 patients (35 males and 35 females) older than 18 years of age were evaluated. To measure the maxillary sinus volume, axial CBCT sections with $2 \mathrm{~mm}$ slice thickness and Digimizer software were used. Sinus volume was calculated using the formula: volume=sum of the thickness of each slice multiplied by the surface area of each slice. The mean width and height of the palate in the coronal plane, anterior-posterior length of the palate in the sagittal plane and distance between the two zygomatic buttresses were measured on the axial CBCT sections in both males and females. The Pearson's correlation coefficient, independent t-test and paired t-test were used for statistical analyses. The mean maxillary sinus volume was $15.9 \pm 6.05 \mathrm{~cm} 3$ and $13 \pm 2.85 \mathrm{~cm} 3$ in males and females, respectively. The mean volume of the maxillary sinus was larger in males, and a significant correlation was noted between the mean volume of the maxillary sinus and width and height of the palate as well as the distance between the two zygomatic buttresses $(\mathrm{P}<0.05)$. Despite the larger volume of the maxillary sinus in males, this parameter cannot be used for sexual identification because the area under the receiver operating curve (ROC) was 62.7\%.
\end{abstract}

KEY WORDS: CONE-BEAM COMPUTED TOMOGRAPHY; SEXUAL IDENTIFICATION; MAXILLARY SINUS

\section{ARTICLE INFORMATION:}

"Corresponding Author:

Received $19^{\text {th }}$ July, 2017

Accepted after revision $28^{\text {th }}$ Sep, 2017

BBRC Print ISSN: 0974-6455

Online ISSN: 2321-4007 CODEN: USA BBRCBA

Thomson Reuters ISI ESC and Crossref Indexed Journal

NAAS Journal Score 2017: 4.31 Cosmos IF: 4.006

${ }^{\circ}$ A Society of Science and Nature Publication, 2017. All rights reserved.

Online Contents Available at: http//www.bbrc.in/

DOI: $10.21786 / \mathrm{bbrc} / 10.3 / 36$ 


\section{INTRODUCTION}

Maxillary sinus is an irregular cavity within the maxillary bone, which develops under the orbit. Development of the maxillary sinus starts in the third week of pregnancy and continues to the pubertal period (Wang et al. 1994). Accurate measurement of the maxillary sinus volume may be helpful prior to sinus floor augmentation for implant placement (Gray et al.2000). Maxillary sinus volume is variable and thus, is a topic of interest for surgeons particularly the oral and maxillofacial surgeons (Fernandes, 2004). Recently, demand for sexual identification in forensic medicine has increased due to an increase in rate of crime (Saccucci et al.2015). The correlation of volumetric analyses of the maxillary sinus and sexual identification has been a controversial topic (Ariji et al. 1994; Jasim et al. 2013; Vidya et al. 2013; Ekizoglu et al.2014; Möhlhenrich et al. 2015).

Conventional radiographs are not accurate for determination of the volume of the maxillary sinus due to the superimposition of images of other paranasal sinuses and craniofacial skeleton on the superior part of the maxillary sinuses (Wolf et al.1993). Considering the complex structure of the sinus, magnetic resonance imaging and computed tomography (CT; gold standard) are used for three-dimensional visualization of the sinus anatomy. However, their use is limited due to high patient radiation dose (CT), limited access and high cost (Schwab et al.1998; Lenza et al.2010). Thus, this study aimed to measure the volume of the maxillary sinus using cone beam computed tomography (CBCT) and assess its association with gender and some craniofacial indices.

\section{MATERIAL AND METHODS}

This study was conducted on CBCT scans of the right and left maxillary sinuses of 70 patients including 35 females and 35 males over 18 years of age, who presented to the Oral and Maxillofacial Radiology Department of Islamic Azad University, Isfahan branch. Images with optimal quality were chosen. All images had been taken with the same CBCT unit (Galileos-Sirona, Bensheim, Germany) with high resolution and $0.1 \mathrm{~mm}$ voxel size and exposure settings of $85 \mathrm{kV}$ and 21-35 mAs (based on the patient's weight) and were analyzed using SIDEXIS software. Patients with a history of surgery or facial asymmetry, completely or partially edentulous patients, those with inflammatory diseases of the sinus such as sinusitis, periodontal patients, those with tumors such as angioma, squamous cell carcinoma and lymphoma, history of facial bone fracture, cysts, infection and sinus polyps were excluded.

Distance between the zygomatic buttresses: Distance between the zygomatic buttresses was calculated on axial sections of the upper midface according to a study by Ariji et al. [9] and Waitzman et al.(1992). To calculate this distance, on axial sections visualizing the inferior border of the zygomaticomaxillary suture, a horizontal line was drawn connecting the outermost points of the zygomatic buttresses in the two sides and its length was measured in millimeters (Figure 1a).

Width and height of the palate: To calculate the palatal width on coronal sections according to Byasalet al. (2011), a horizontal line was drawn from the palatal margin of the crestal bone of the first molar tooth in one side to the palatal margin of the crestal bone of the other side and its length was measured. To measure the height of the palate in this region on coronal sections, as shown in Figure 1b, a line was drawn from the palate perpendicular to the line connecting the alveolar crest borders of the two sides and its length was measured.

Length of the hard palate: To measure the length of the hard palate on sagittal sections, the distance between the anterior nasal spine and posterior nasal spine at the midline (where the anterior nasal spine was visible) was measured (Figure 3C).

Maxillary sinus volume: To measure the maxillary sinus volume, axial CBCT sections with $2 \mathrm{~mm}$ slice thickness and $2 \mathrm{~mm}$ intervals were used. The CBCT sections were subjected to Digimizer version 4.1.1 software and the surface area of the sinus was automatically measured and stored in Excel format. The surface area of all sections of the sinus (about 20 to 25 sections) in both sides was calculated for each patient. Then, to calculate the volume of the sinus in cubic centimeters, the following formula was used: Sum of the surface area of the sinus in each section $\times$ thickness of each section (Figure 2). Data were collected and analyzed using SPSS version 24.Independentt-test and paired t-test were used to compare differences in the right and left sides and in the mean size of variables.

\section{RESULTS AND DISCUSSION}

Two groups $(n=35)$ of males and females in the age range of 18 to 74 years were evaluated. The mean age was 37.2 years in females and 34.3 years in males. Independent t-test showed that the mean age of males and females was not significantly different $(\mathrm{P}=0.30)$. The mean volume of the maxillary sinus was $14.45 \pm 2.71 \mathrm{~cm}^{3}$. Independent t-test showed that the mean volume of the sinus in the right $(\mathrm{P}=0.02)$, left $(\mathrm{P}=0.006)$ and both $(\mathrm{P}=0.01)$ sides was significantly greater in males than females. In other words, a significant association existed between gender and maxillary sinus volume in the right and left sides $(\mathrm{P}<0.05$, Table 1$)$.

The area under the ROC curve was 0.627 or $62.7 \%$ (smaller than 0.70) (Graph 1). 


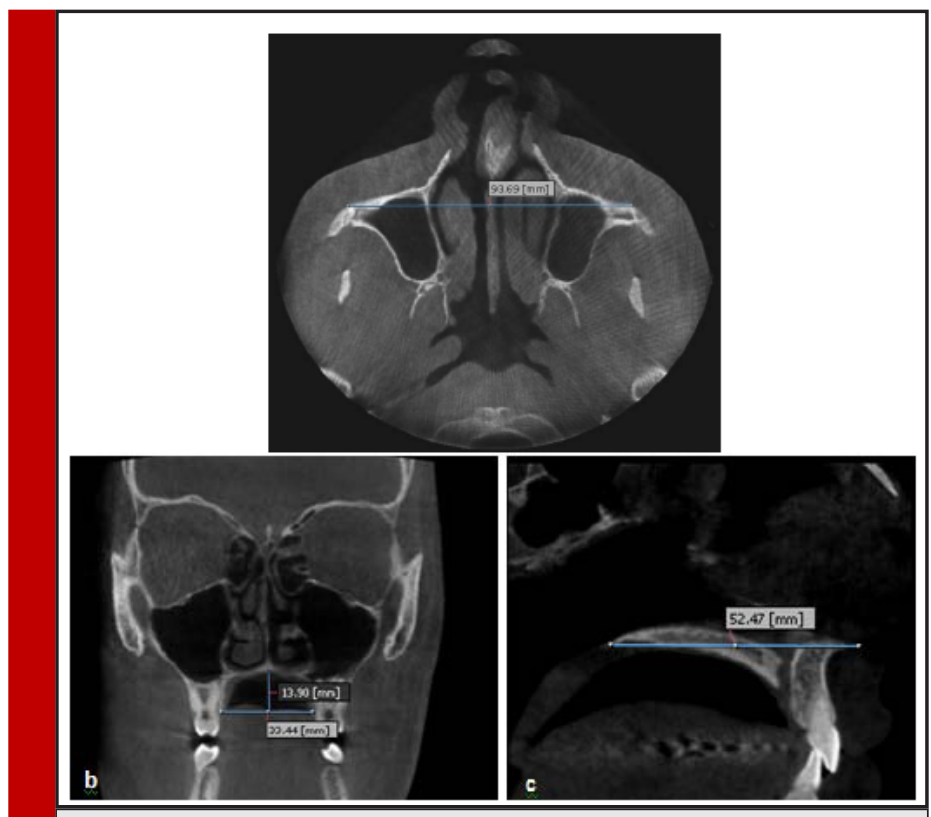

FIGURE 1. (a) Distance between the two zygomatic buttresses. (b) Measurement of the width and height of the palate at the maxillary first molar site. (C) Measurement of the anterior-posterior length of the hard palate

Paired t-test showed that the mean volume of the maxillary sinus in the right and left sides in females $(\mathrm{P}=0.61)$, males $(\mathrm{P}=0.68)$ and in total $(\mathrm{P}=0.92)$ was not significantly different (Table 2 ).

Independent t-test showed that the mean anterior-posterior length of the palate in sagittal plane was not significantly different between males and females $(\mathrm{P}=0.23)$ but the mean distance between the two zygomatic buttresses in the axial plane $(\mathrm{P}<0.001)$, palatal width in the first molar region in the coronal plane $(\mathrm{P}=0.007)$ and height of the palate in the first molar region in the coronal plane $(\mathrm{P}=0.002)$ were significantly greater in males than in females. Thus, no significant association existed between gender and anterior-posterior length of the palate in sagittal plane; but gender had a significant association with the other three variables (Table 3).

The Pearson's correlation coefficient showed that no significant association existed between age and vol-

\begin{tabular}{|c|c|c|c|c|c|c|}
\hline \multirow[b]{2}{*}{ Side } & \multicolumn{2}{|c|}{ Females } & \multicolumn{2}{|c|}{ Males } & \multicolumn{2}{|c|}{ Independent t-test } \\
\hline & Mean & $\begin{array}{l}\text { Standard } \\
\text { deviation }\end{array}$ & Mean & $\begin{array}{l}\text { Standard } \\
\text { deviation }\end{array}$ & $\mathrm{t}$ & $P$ value \\
\hline Right & $13 / 1$ & $2 / 9$ & $15 / 8$ & $6 / 3$ & $2 / 31$ & $0 / 02$ \\
\hline Left & $12 / 9$ & $2 / 8$ & $16 / 01$ & $5 / 8$ & $2 / 86$ & $0 / 006$ \\
\hline Total & 13 & $2 / 85$ & $15 / 9$ & $6 / 05$ & $2 / 58$ & $0 / 01$ \\
\hline
\end{tabular}

\begin{tabular}{|c|c|c|c|c|c|c|}
\hline \multirow[b]{2}{*}{ Gender } & \multicolumn{2}{|c|}{ Right } & \multicolumn{2}{|c|}{ Left } & \multicolumn{2}{|c|}{ Independent t-test } \\
\hline & Mean & $\begin{array}{l}\text { Standard } \\
\text { deviation }\end{array}$ & Mean & $\begin{array}{l}\text { Standard } \\
\text { deviation }\end{array}$ & $\mathrm{t}$ & $P$ value \\
\hline Females & $13 / 1$ & $2 / 9$ & $12 / 9$ & $2 / 8$ & $0 / 51$ & $0 / 61$ \\
\hline Males & $15 / 8$ & $6 / 3$ & 16/01 & $5 / 8$ & $0 / 41$ & $0 / 68$ \\
\hline Total & $14 / 4$ & $55 / 1$ & $14 / 5$ & $4 / 8$ & $0 / 09$ & $0 / 92$ \\
\hline
\end{tabular}




\begin{tabular}{|l|c|c|c|c|c|c|}
\hline \multirow{2}{*}{ Table 3. Comparison of the mean craniofacial parameters in males and females (in mm) } \\
\cline { 2 - 8 } & Mean & $\begin{array}{c}\text { Standard } \\
\text { deviation }\end{array}$ & Mean & $\begin{array}{c}\text { Standard } \\
\text { deviation }\end{array}$ & $\mathrm{t}$ & P value \\
\hline $\begin{array}{l}\text { Distance between zygomatic } \\
\text { buttresses in axial plane }\end{array}$ & $85 / 2$ & $4 / 2$ & $88 / 9$ & $4 / 1$ & $3 / 70$ & $<0 / 001$ \\
\hline $\begin{array}{l}\text { Anterior posterior length of the } \\
\text { palate in sagittal plane }\end{array}$ & $51 / 2$ & $3 / 2$ & $52 / 6$ & $6 / 1$ & $1 / 20$ & $0 / 23$ \\
\hline $\begin{array}{l}\text { Width of the palate in first } \\
\text { molar site in coronal plane }\end{array}$ & $33 / 2$ & $2 / 6$ & $34 / 9$ & $2 / 8$ & $2 / 79$ & $0 / 007$ \\
\hline $\begin{array}{l}\text { Height of the palate in the first } \\
\text { molar site in coronal plane }\end{array}$ & $11 / 8$ & $1 / 7$ & $13 / 8$ & $3 / 3$ & $3 / 25$ & $0 / 002$ \\
\hline
\end{tabular}

\begin{tabular}{|c|c|c|}
\hline \multirow{2}{*}{ Variable } & \multicolumn{2}{|c|}{ Maxillary sinus volume } \\
\hline & $\mathrm{r}$ & $P$ value \\
\hline Age & $-0 / 182$ & $0 / 18$ \\
\hline Distance between zygomatic buttresses in axial plane & $0 / 424$ & $<0 / 001$ \\
\hline Anterior posterior length of the palate in sagittal plane & $0 / 119$ & $0 / 33$ \\
\hline Width of the palate in first molar site in coronal plane & $0 / 241$ & $0 / 044$ \\
\hline $\begin{array}{l}\text { Height of the palate in the first molar site in coronal } \\
\text { plane }\end{array}$ & $0 / 547$ & $<0 / 001$ \\
\hline
\end{tabular}

ume of the maxillary sinus $(\mathrm{P}=0.18)$. The anterior-posterior length of the palate in the sagittal plane had no significant association with the maxillary sinus volume $(\mathrm{P}=0.33)$. But an association existed between the palatal width in the first molar site in the coronal plane and the volume of the maxillary sinus $(\mathrm{P}=0.044)$. The Pearson's correlation coefficient showed that a significant association existed between the distance between the two zygo- matic buttresses in the axial plane and also the height of the palate in the first molar region in the coronal plane with the volume of the maxillary sinus $(\mathrm{P}<0.001$, Table 4).

Maxillary sinus is the closest paranasal sinus to the oral cavity and since implant treatments along with open or closed sinus lift surgery (due to pneumatization of the maxillary sinus) have greatly increased, knowledge about the anatomy of the maxillary sinus is impor-

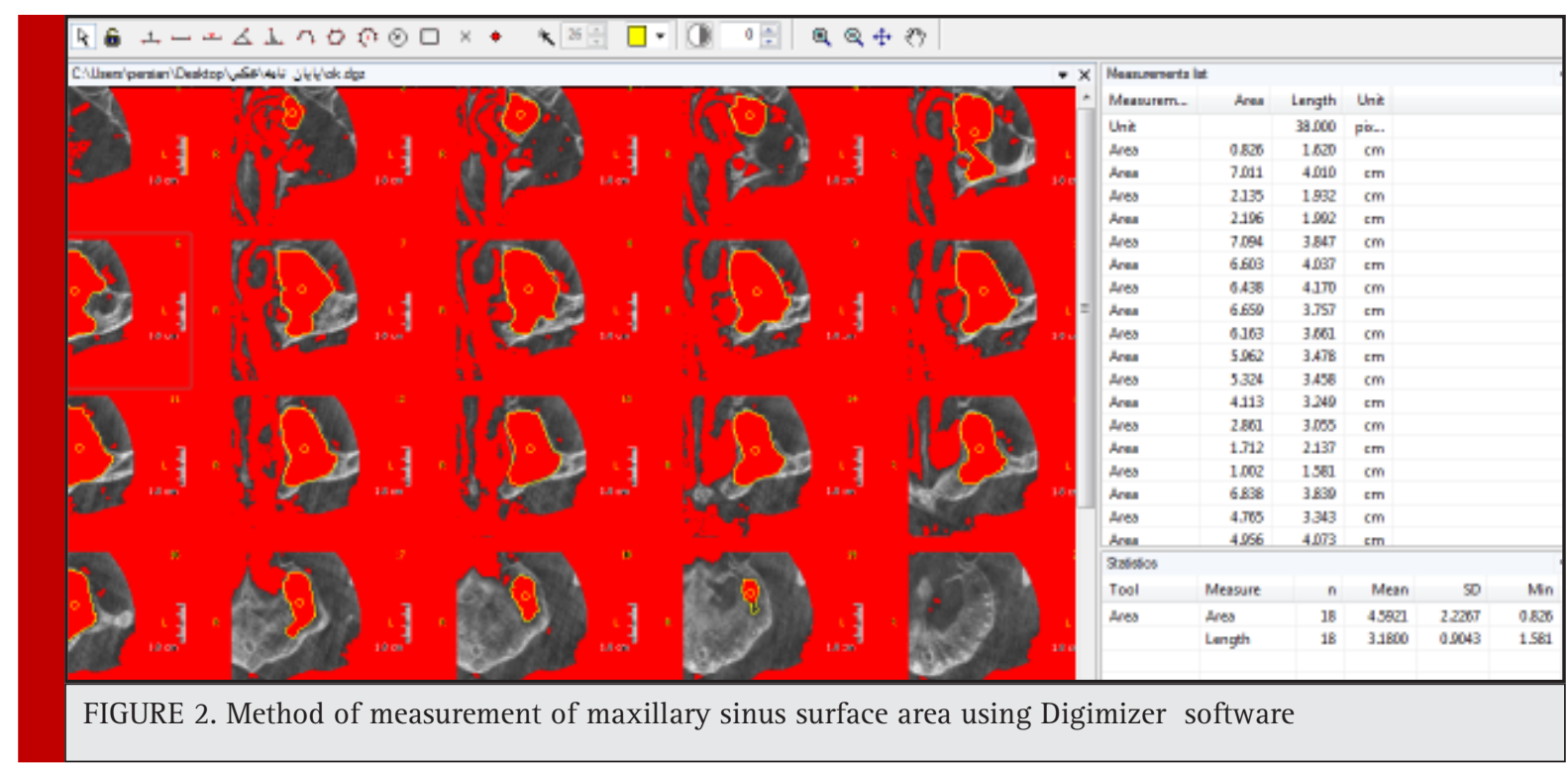




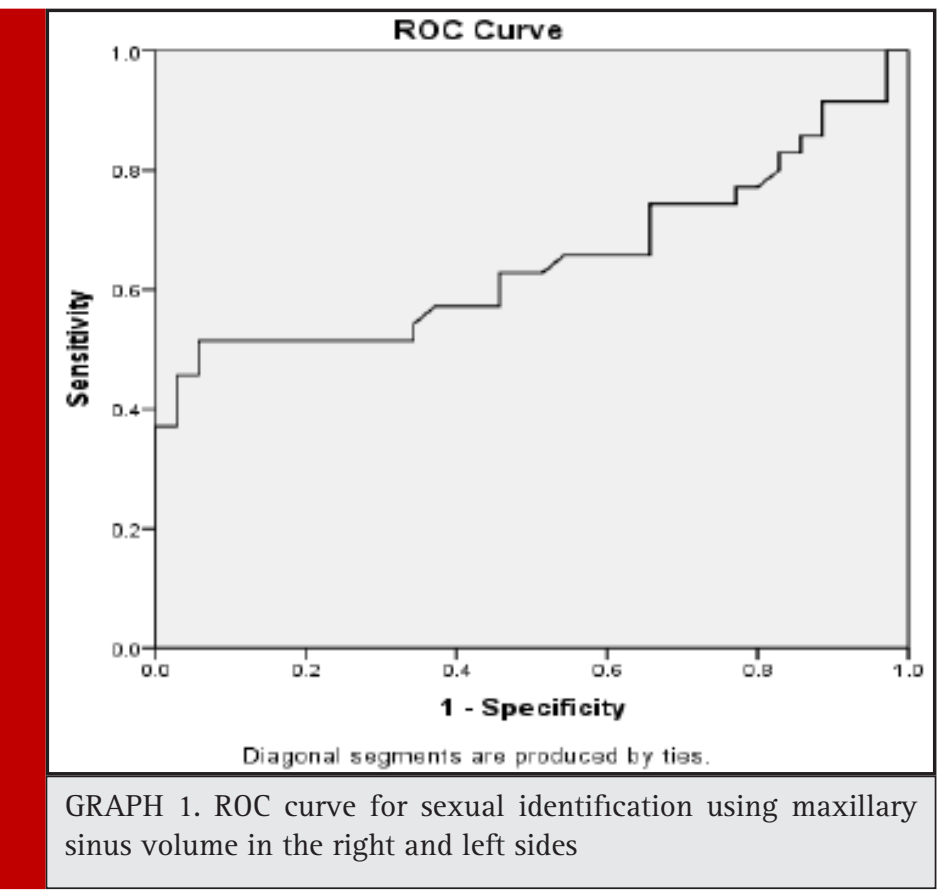

tant (Gray et al. 2000). Sexual identification is an important parameter in forensic medicine. Use of maxillary sinus dimensions measured on CT scans may help in this regard in cases where other methods fall short; however, this method has its own drawbacks as well (Lerno, 1983). Since a decade ago, CBCT is recommended as a modality for maxillofacial imaging (Farman et al. 2006; Moreira et al. 2009). This modality enables image reconstruction without superimposition and has lower patient radiation dose compared to CT (Moreira et al. 2009). It is believed that the quality of CBCT images is equal to that of conventional $\mathrm{CT}$ in visualization of maxillofacial structures (Silva et al. 2008; Loubele et al. 2009; Carrafiello et al. 2010).

In our study, the mean volume of the right maxillary sinus was $14.4 \pm 5.1 \mathrm{~cm}^{3}$ and the mean volume of the left maxillary sinus was $14.5 \pm 4.8 \mathrm{~cm}^{3}$. Also, maxillary sinus volume in males was significantly greater than that in females $(\mathrm{P}<0.05)$. In 2013, Jasim et al. measured the volume and dimensions of the maxillary sinus and evaluated its association with age and gender using CT. They reported that the volume and dimensions of the maxillary sinus in males were greater than that in females and volume of the sinus decreased by an increase in age (Jasim et al. 2013). To calculate the volume of the maxillary sinus, they used a method similar to ours; however, in our study in contrast to theirs, no significant association was found between age and volume of the maxillary sinus $(\mathrm{P}=0.30)$. This difference may be due to the age group of patients since Jasim et al. (2013) evaluated patients in older age group (40-69 years).
In 2016, Prabhat et al. evaluated the size and volume of the maxillary sinus and its association with sexual identification using CT. They reported that volume of the maxillary sinus in males was significantly greater than that in females. They stated that use of maxillary sinus volume increases the accuracy of sexual identification by $83.3 \%$ (Prabhat et al. 2016). In our study, volume of the maxillary sinus in males was greater than that in females. However, since the area under the ROC curve was $62.7 \%(<70 \%)$, maxillary sinus volume cannot be used as a reliable indicator for sexual identification. These differences in measurements may be due to anatomical differences of the sinus in different geographical areas and among different races. Another reason may be the difference in method of calculation of sinus volume and sample size, since our sample size was twice as big as that of Prabhat et al.(2016).

Senturk et al. in 2015 evaluated the effect of weather and altitude on volume of the paranasal sinuses and found no significant association between the volume of the maxillary sinus and age or between the size of the sinus in the two sides (Sahlstrand-Johnson, 2011). In our study, no significant difference was noted between the volume of the maxillary sinus and age or between the volume of the maxillary sinuses in the two sides $(P>0.05)$. Ariji et al. in 1993 evaluated the correlation of the maxillary sinus volume and aging and found that the mean volume of the right and left maxillary sinuses was $14.64 \pm 6.32 \mathrm{~cm}^{3}$. They found no significant difference in the volume of the maxillary sinus between males and females. Sinus volume had an ascending trend to 
20 years of age and then decreased. They also reported that a significant association exists between the volume of the maxillary sinuses and the distance between the two zygomatic buttresses and the zygomatic occipital distance (Ariji et al. 1994). The maxillary sinus volume reported by Arihi et al. (1994) was comparable to the value obtained in our study $\left(14.45 \pm 2.71 \mathrm{~cm}^{3}\right)$.

However, in our study, the volume of the maxillary sinus in males was significantly higher than that in females and no significant association was noted between the sinus volume and age. In our study, aside from the relationship of the maxillary sinus volume with age and sex, its correlation with some other craniofacial parameters such as width and height of the palate in the first molar area in the coronal plane, anterior-posterior length of the palate in the sagittal plane and the distance between the two zygomatic buttresses in the axial plane was also evaluated and it was found that a correlation existed between the volume of the maxillary sinus and the distance between the two zygomatic buttresses; this finding was comparable to that of Ariji et al. Moreover, it was found that the greater the width and height of the palate, the greater the size of the maxillary sinus would be $(\mathrm{P}<0.05)$. But no significant correlation was found between the sinus volume and the anterior-posterior length of the hard palate $(\mathrm{P}>0.05)$.

\section{CONCLUSION}

The current results showed that Despite the presence of a significant association between gender and volume of the maxillary sinus $(\mathrm{P}<0.05)$, since the area under the ROC curve was 0.627 or $62.7 \%$ (smaller than 0.70 ), volume of the maxillary sinus cannot serve as a definite and reliable indicator for sexual. Also, a correlation was noted between the maxillary sinus volume and width and height of the palate at the first molar site and the distance between the two zygomatic buttresses.

\section{REFERENCES}

Ariji Y, Kuroki T, Moriguchi S, Ariji E, Kanda S. (1994). Age changes in the volume of the human maxillary sinus: a study using computed tomography. Dentomaxillofacial radiology 23(3): 163-8.

Baysal A, Veli I, Ucar FI, Eruz M, Ozer T, Uysal T. (2011). Changes in mandibular transversal arch dimensions after rapid maxillary expansion procedure assessed through cone-beam computed tomography. Korean Journal of Orthodontics 41(3): 200-10.

Carrafiello G, Dizonno M, Colli V, Strocchi S, Taubert SP, Leonardi A, et al. (2010). Comparative study of jaws with multislice computed tomography and cone-beam computed tomography. La radiologia medica 115(4): 600-11.
Ekizoglu 0, Inci E, Hocaoglu E, Sayin I, Kayhan FT, Can IO. (2014). The use of maxillary sinus dimensions in gender determination: a thin-slice multidetector computed tomography assisted morphometric study. Journal of Craniofacial Surgery 25(3): 957-60.

Farman AG, Scarfe WC. (2006). Development of imaging selection criteria and procedures should precede cephalometric assessment with cone-beam computed tomography. American Journal of Orthodontics and Dentofacial Orthopedics 130(2): 257-65.

Fernandes C. (2004). Volumetric analysis of maxillary sinuses of Zulu and European crania by helical, multislice computed tomography. The Journal of Laryngology \&t Otology 118(11): 877-81.

Gray C, Staff R, Redpath T, Needham G, Renny N. (2000). Assessment of maxillary sinus volume for the sinus lift operation by three-dimensional magnetic resonance imaging. Dentomaxillofacial Radiology 29(3): 154-8.

Jasim HH, Al-Taei JA. (2013). Computed tomographic measurement of maxillary sinus volume and dimension in correlation to the age and gender (comparative study among individuals with dentate and edentulous maxilla). Journal of Baghdad College of Dentistry 25(1): 87-93.

Lenza M, Lenza Md0, Dalstra M, Melsen B, Cattaneo P. (2010). An analysis of different approaches to the assessment of upper airway morphology: a CBCT study. Orthodontics \&t craniofacial research 13(2): 96-105.

Lerno P. (1983). Identification par le sinus maxillaire. Odontol leg. 216:39-40.

Loubele M, Bogaerts R, Van Dijck E, Pauwels R, Vanheusden S, Suetens P, et al. (2009). Comparison between effective radiation dose of CBCT and MSCT scanners for dentomaxillofacial applications. European journal of radiology 71(3): 461-8.

Möhlhenrich SC, Heussen N, Peters F, Steiner T, Hölzle F, Modabber A. (2015). Is the Maxillary Sinus Really Suitable in Sex Determination? A Three-Dimensional Analysis of Maxillary Sinus Volume and Surface Depending on Sex and Dentition. Journal of Craniofacial Surgery 26(8) :723-6.

Moreira CR, Sales MA, Lopes PM, Cavalcanti MG. (2009). Assessment of linear and angular measurements on threedimensional cone-beam computed tomographic images. Oral Surgery, Oral Medicine, Oral Pathology, Oral Radiology, and Endodontology 108(3): 430-6.

Prabhat M, Rai S, Kaur M, Prabhat K, Bhatnagar P, Panjwani S. (2016). Computed tomography based forensic gender determination by measuring the size and volume of the maxillary sinuses. Journal of forensic dental sciences 8(1): 40.

Saccucci M, Cipriani F, Carderi S, Di Carlo G, D'Attilio M, Rodolfino D, et al. (2015). Gender assessment through threedimensional analysis of maxillary sinuses by means of Cone Beam Computed Tomography. European review for medical and pharmacological sciences 19(2): 185-93.

Schwab RJ. (1998). Upper airway imaging. Clinics in chest medicine. 19(1):33-54. 
Sentürk M, Azgin I, Öcal R, Sakarya EU, Güler I. (2015). Volumetric analysis of the maxillary sinus in pediatric patients with nasal septal deviation. ENT Updates 5(3): 107.

Silva MAG, Wolf U, Heinicke F, Bumann A, Visser H, Hirsch E. (2008). Cone-beam computed tomography for routine orthodontic treatment planning: a radiation dose evaluation. American Journal of Orthodontics and Dentofacial Orthopedics 133(5): 640-5.

Vidya C, Shamasundar N, Manjunatha B, Raichurkar K. (2013). Evaluation of size and volume of maxillary sinus to determine gender by 3D computerized tomography scan method using dry skulls of South Indian origin. International Journal of Current Research and Review 5(3): 97.
Waitzman AA, Posnick JC, Armstrong DC, Pron GE. (1992). Craniofacial skeletal measurements based on computed tomography: Part II. Normal values and growth trends. The Cleft palate-craniofacial journal 29(2): 118-28.

Wang R-G, Jiang S, Gu R. (1994). The cartilaginous nasal capsule and embryonic development of human paranasal sinuses. The Journal of otolaryngology 23(4): 239-43.

Wolf G, Anderhuber W, Kuhn F. (1993). Development of the paranasal sinuses in children: implications for paranasal sinus surgery. Annals of Otology, Rhinology \& Laryngology 102(9): 705-11. 